\title{
A Theory-guided research agenda for physics teacher education
}

\author{
Eugenia Etkina ${ }^{1}$, Bor Gregorcic ${ }^{2}$, and Stamatis Vokos ${ }^{3,4}$ \\ ${ }^{1}$ Graduate School of Education, Rutgers University, 10 Seminary Place, New Brunswick, NJ 08901-1183, USA \\ ${ }^{2}$ Department of Physics and Astronomy, Uppsala University, Box 516, 75120 Uppsala, Sweden \\ ${ }^{3}$ Department of Physics, Seattle Pacific University, Seattle, Washington 98119, USA \\ ${ }^{4}$ Department of Physics, California Polytechnic State University, San Luis Obispo, California 93407, USA
}

\begin{abstract}
We have proposed a conceptual framework aimed at providing a better understanding and possible improvement of the process of physics teacher formation. Existing literature on teacher preparation suggests that pre-service teachers (PSTs) learn best when they are immersed in a community, which shares a common vision of what good teaching entails, and helps PSTs develop requisite knowledge, skills, and dispositions consistent with that vision. However, the time pressures and complexities of the teaching profession are such that a teacher cannot afford multiple considerations and deliberations with oneself before every decision. We therefore suggest that good teacher preparation programs should, in addition to the requisite knowledge, skills and dispositions, strive to develop in PSTs productive habits (spontaneous responses to situational cues). In this paper, we propose a research agenda for testing the proposed framework in the context of physics teacher preparation. The agenda revolves around examples of teaching habits that illustrate the unique character of physics teaching,.
\end{abstract}

\section{INTRODUCTION}

A plethora of papers, books, reports and accreditation standards, all of which are concerned with the characteristics of effective teachers, convey a set of complex patterns relevant for the preparation of future teachers. However, until recently, the literature has been missing a coherent conceptual explanation for why these patterns emerge. To address this issue the authors of this paper developed the DHAC framework (Development of Habits through Apprenticeship in a Community) [1]. The framework aims to provide a more fundamental conceptualization of both the characteristics of good teachers, as well as the mechanisms of teacher education, which have those characteristics as their intended outcome. While the DHAC framework is, on the structural level, fairly general and applicable to different subject domains, it does not become useful until it is instantiated in a subjectspecific domain. In fact, physics, with its rich canon of education research, has in crucial ways fed into the development of the DHAC framework.

Certain topics have appeared with great regularity, both in the general, as well as the physics-specific literature on successful teacher preparation programs. Teacher preparation should: attend to pre-service teachers' dispositions (attitudes and beliefs about teaching and learning, students, etc.) [2-4], provide sufficient duration and coherence with compelling vision $[3,5,6]$, develop knowledge (with emphasis on subject-specific content knowledge for teaching) $[3,5,7,8]$, provide opportunities for teaching experience $[3,6,7,9]$, shape a community of teachers and learners $[6,10-12]$, and prepare for life-long learning $[6,7,9]$. The common denominator of both general and physics-specific [8] recommendations seem to be a focus on providing PSTs with prolonged, thorough, and extensive experience.

The characteristics listed above and extant attempts at formulating a theory of teacher education $[6,9]$ are the footholds of the DHAC framework.

\section{THE DHAC FRAMEWORK: AN OVERVIEW}

The DHAC framework brings together the existing body of literature on teacher education (general and physicsspecific), by proposing a mechanism that attempts to unify the empirically found features of promising teacher preparation programs and existing theoretical perspectives on teacher preparation.

We argue that while the development of productive dispositions, knowledge and skills should be the aim of any teacher preparation program, their development is not sufficient if the new teachers are to enter the teaching profession well prepared for dealing with everyday challenges of teaching. 
The unpredictable circumstances, complexities and time pressures of classroom life compel teachers to develop a system of spontaneous responses to situational cues $[13,14]$. We refer to these spontaneous responses as habits $[15,16]$. While any teacher will develop habits in response to their environment, these habits may, if the teacher enters the profession unprepared, be directed toward teacher "survival", instead of student learning. The DHAC framework suggests that teachers should enter the profession with an existing "toolbox," a beginning repertoire, of productive habits, developed in the teacher preparation program.

In the DHAC framework we therefore conceptualize both a well-prepared physics teacher, as well as the process of his or her the preparation. We do this with the help of an illustrative analogy of a tree (the teacher) growing in an environment (the community of people engaged in the teacher-preparation program) (see Fig. 1).

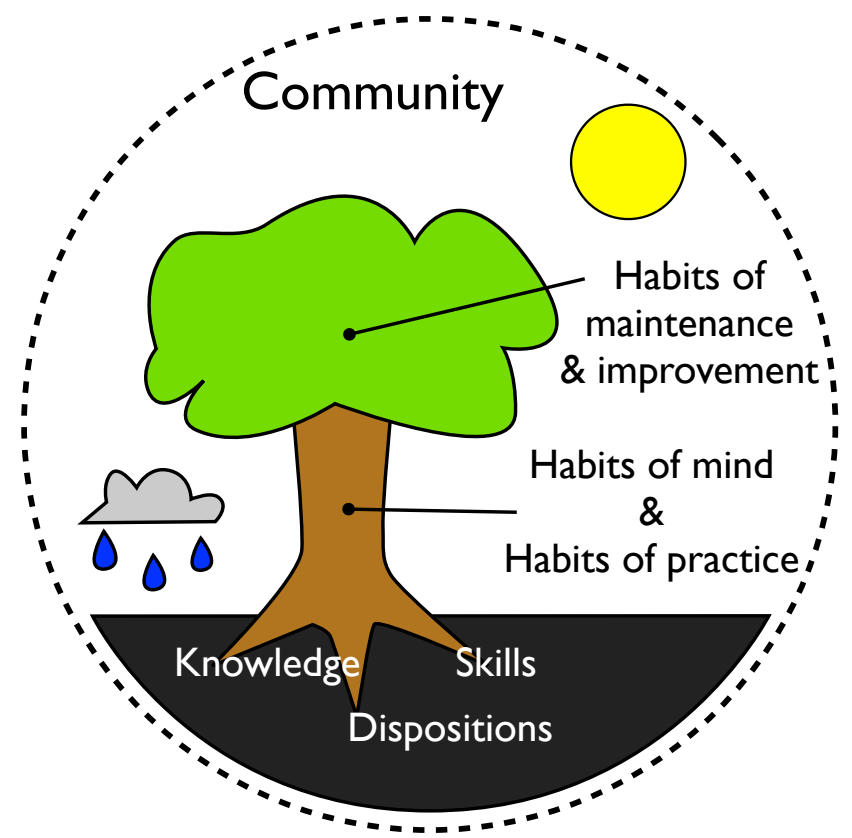

FIG. 1. An illustrative analogy of a teacher (the tree) developing in a community (the environment) of mentors and other students in the teacher-preparation program.

The roots of the tree represent the teacher's grounding in the relevant dispositions, knowledge and core skills. The trunk represents the habits of mind and practice that the teacher will use to guide his or her work. The canopy is where the tree grows, and it represents the teacher's ability to grow professionally. The community should therefore nurture the teacher with appropriate "nutrients" and provide it with opportunities to develop productive habits by exposing it, in incremental and structured ways, to real teaching situations in order to strengthen his or her ability to handle authentic situations in the fog of war - the classroom. This can be done, for example using microteaching at the beginning and classroom placement with experienced mentors towards the end of the program [11].

While the DHAC framework is relatively general on a structural level, its content, that is, the necessary habits required for a well-prepared teacher, are both general, as well as subject specific. The subject-particular worldviews, which are reflected in the signature pedagogies of different subjects, including physics [17], are reflected in all components of the framework. To be useful for informing physics teacher preparation, the DHAC framework needs to be furnished with habits relevant for the teaching of physics. In the next section we present examples of habits, and link them to the underlying knowledge, skills and dispositions from which they emerge.

\section{THE ROLE OF KNOWLEDGE, SKILLS, AND DISPOSITIONS IN THE FORMATION OF HABITS}

To give the reader a taste of what we have in mind in the limited space of this article, we chose several important habits of a well-prepared physics teacher that PSTs should develop before they start teaching physics in school and showed how knowledge skills and dispositions are necessary for the formation of these habits The list of habits is based on the analysis of the literature and personal experiences of the authors.

Habits of mind refer to the reasoning like an expert in a variety of situations related to learning, habits of practice refer to making and enacting decisions during lesson preparation and in-class instruction that are consistent with promoting student learning, and reflecting on one's actions and student learning after each lesson and habits of maintenance and improvement refer to continuously engaging in personal and communal reflection and professional development, and exercising multivalent leadership roles to improve habits of mind and ensure the general wellbeing of all students. We separate habits of mind and practice into (a) physics habits of mind and (b) physics teacher habits of mind and practice.

Example of a physics habit of mind: As a physicist, a physics teacher should see physics principles applied "everywhere" (for example, thinking of static friction when walking, noticing diffraction pattern on eye lashes when squinting, etc.)

Such a habit can only develop if the PST:

1. Believes it is the right thing to do (disposition).

2. Knows physics well enough to connect formal principles to everyday phenomena (knowledge).

3. Is skilled in noticing and capturing "cases of physics" in everyday situations (e.g. videos of observed phenomena, making quick order-of-magnitude estimations, etc.) (skills). 
Two other examples of physics habits of mind are approaching problem solving as a physicist and treating physics as a process, not a set of rules or a collection of information.

Example of a physics teacher habit of mind and practice: A physics teacher should habitually encourage students to test their ideas experimentally instead of waiting for validation from authority. In physics, it is often easy and highly productive to say, "Think of how you can test your idea experimentally. Then go ahead and try it; set it [e.g., bulbs, cart, magnet] up and see whether what you think should happen, happens." In chemistry, such quick testing may not be possible, and in biology, it is very unlikely to be possible; that is, you would need to make a different "spontaneous decision."

Such a habit can only be developed if the PST:

1. Believes this is the right thing to do (disposition),

2. Knows in detail the physics content and challenges it presents to students and anticipates possible student ideas and suggestions, knows possible productive experiments that will allow the students to test these ideas (knowledge).

3. Is skilled in selecting, preparing, maintaining and repairing equipment to be used in classroom experiments so that the students can test their ideas quickly and efficiently (skills).

Two other examples of physics teacher habits of mind are seeking to establish a step-by-step causal chain to understand a particular phenomenon instead of just describing the phenomena by collecting and analyzing data and treating all students as capable of learning physics and contributing to the generation of physics knowledge (as opposed to treating learning physics as a weed-out competition).

Example of a physics teacher habit of maintenance and improvement: In addition to the expectation that a physics teacher would be an active member of the AAPT or its regional chapter (or similar physics-teaching organization or society), the teacher should habitually seek out leadership opportunities within teaching physics as an inclusive process of inquiry, and habitually read literature aimed at physics teachers (e.g. The Physics Teacher (TPT)). Such habit can only develop if a PST:

1. Believes it is the right thing to do (disposition).

2. Is familiar with AAPT, has attended AAPT national or regional meetings and has read articles from TPT as a part of participation in the program (knowledge).

3. Is skilled in working with like-minded colleagues to apply ideas presented in physics teacher journals to classroom activities, assessments, etc. (skills)

We provided the above examples of habits and their grounding in the requisite dispositions, knowledge and skills as an illustration of the importance of subject-specific furnishing of the DHAC model with concrete, physicsrelevant habits of mind, practice and maintenance. There are other important habits, which we do not list here because of spatial limitations.

The development of productive habits in prospective physics teachers is thus the foundational responsibility of physics teacher preparation programs. We hypothesize that the empirically found characteristics of successful teacher preparation programs (including physics $[8,18]$ ) can be better understood in light of the DHAC framework. Most notably we may explain the centrality of continuity and duration, as well as the importance of a nurturing community by conceptualizing teacher preparation as apprenticeship in a community.

Having thought of habit development as a major goal of the physics teacher preparation program we can now build programs that purposefully focus on those habits and help pre-service teachers develop them through course work, clinical practice and involvement in professional learning communities. As the habits need time and repeated exposure to develop, teacher preparation programs need to be sufficient in length, coherence and provide multiple exposures to opportunities to cement productive habits.

\section{FUTURE RESEARCH AGENDA}

Because the theoretical model we have proposed is eminently testable, we offer it to the community as a way to organize a multi-faceted future research agenda for the field. There is a need to:

1. Observe ethnographically and interview master teachers to document their detailed habits of mind, practice and maintenance

The substantive enumeration of the habits of mind of a physicist and a physics teacher remains elusive despite some efforts to operationalize what it means to think like a physicist [17,19-21]. In view of a serious and urgent need to make the physics enterprise reflect the rich diversity of the population, additional research is needed to understand the interplay of human characteristics such as gender, gender expression, race, and ethnicity with the habits of mind of diverse master teachers. Additional research is needed.

2. Update continuously the repertoire of productive habits and document productive ways to develop them efficiently.

We do not know yet how to characterize new productive habits or how to help PSTs develop them in an efficient manner. Additional research is needed.

3. Test activities to help PSTs develop desired habits and performance assessments to find whether PSTs are developing (or are on the path to development of) those habits.

Physics education researchers have had considerable experience assessing whether or not (and the extent to 
which) a conceptual or problem solving skill has been developed after instruction. Additional research is needed to help us "see" the beginnings of a habit in moment-bymoment practice. Once we learn to recognize the attributes of a specific habit as it is forming, we can test causation hypotheses and attempt to precipitate positive change more effectively.

4. Marshall evidence that the specific habits that the program is attempting to form actually form - for this we need to study graduates of different programs to connect their teaching to what the program was attempting to help them learn.

To our knowledge, no systematic research has been undertaken to connect program outcomes from different programs with specific inputs from the programs. Recent work on developing a framework for operationalizing, validating, and assessing Content Knowledge for Teaching is poised to help the field develop a common language for describing one important outcome of teacher preparation programs. However, further research is needed to connect specific habits that program graduates exhibits and to connect these causally with features of the program.
5. Connect the documented carrying out of habits in the classroom to student learning, student affect, and student physics identity.

Perhaps most daunting of all steps in the research agenda is the logistically difficult but crucial step of connecting teacher habits to precollege student outcomes. Yet, without this piece, which teacher characteristics make the largest positive impact on students' multivalent physics experiences will remain elusive.

\section{DISCUSSION}

The major goal of this paper was to present to the PER community a future research agenda that brings to bear PER to physics teacher education efforts. The agenda is grounded in the DHAC framework, which helps us conceptualize and organize features of promising physics teacher education programs. In particular, the model makes a major testable prediction, namely that physics teacher preparation efforts that do not solidify powerful habits are unlikely to produce graduates who are able to help students engage productively and enjoyably in the physics enterprise.
[1] E. Etkina, B. Gregorcic, and S. Vokos, Phys. Rev. Phys. Educ. Res. (in review).

[2] M. Pajares, Rev. Educ. Res. 62, 307 (1992).

[3] E. Etkina, Phys. Rev. ST Phys. Educ. Res. 6, 020110 (2010).

[4] K. E. Gray and V. K. Otero, AIP Conf. Proc. 1179, 149 (2009).

[5] L. C. McDermott, P. S. Shaffer, P. R. L. Heron, M. R. Stetzer, and D. L. Messina, in Recruit. Educ. Futur. Phys. Teach. Case Stud. Eff. Pract., edited by C. Sandifer and E. Brewe (American Physical Society, College Park, MD, 2015), pp. 165-186.

[6] K. Hammerness, L. Darling-Hammond, J. Bransford, D. Berliner, M. Cochran-Smith, M. McDonald, and K. Zeichner, in Prep. Teach. a Chang. World, edited by L. Darling-Hammond and J. D. Bransford (Jossey Bass, San Francisco, 2005), pp. 358-389.

[7] L. Darling-Hammond, K. Hammerness, P. Grossman, F. Rust, and L. Shulman, in Prep. Teach. a Chang. World, edited by L. Darling-Hammond and J. Bransford (JosseyBass, San Francisco, 2005), pp. 390-441.

[8] D. E. Meltzer, in Teach. Educ. Phys. Res. Curriculum, Pract., edited by D. E. Meltzer and P. S. Shaffer (American Physical Society, College Park, MD, 2011), pp. 3-14.

[9] D. L. Ball and D. K. Cohen, in Teach. as Learn. Prof. Handb. Policy Pract., edited by G. Sykes and L. DarlingHammond (Jossey Bass, San Francisco, 1999), pp. 3-32.

[10] L. C. McDermott, Am. J. Phys. 74, 758 (2006).

[11] E. Etkina, in Recruit. Educ. Futur. Phys. Teach. Case Stud. Eff. Pract., edited by C. Sandifer and E. Brewe (American Physical Society, College Park, MD, 2015).
[12] T. Hodapp, J. Hehn, and W. Hein, Phys. Today 62, 40 (2009).

[13] F. Korthagen and B. Lagerwerf, Teach. Teach. 2, 161 (1996).

[14] J. A. Bargh, in Psychol. Action Link. Cogn. Motiv. to Behav., edited by P. Gollwitzer and J. A. Bargh (Guilford Press, New York, NY, 1996), pp. 457-481.

[15] P. J. Nelsen, J. Teach. Educ. 66, 86 (2015).

[16] J. Dewey, Human Nature and Conduct (Dover Publications, Mineola, NY, 2002).

[17] M. J. Lattery, in Explor. Signat. Pedagog. Approaches to Teach. Discip. Habits Mind, edited by R. A. R. Gurung, N. L. Chick, and A. Haynie (Stylus Publishing, Sterling, VA, 2009), pp. 289-294.

[18] C. Sandifer and E. Brewe, editors, Recruiting and Educating Future Physics Teachers: Case Studies and Effective Practices (American Physical Society, College Park, MD, 2015).

[19] A. Van Heuvelen, Am. J. Phys. 59, 891 (1991).

[20] C. Wieman, Phys. Teach. 53, (2015).

[21] M. Poklinek Čančula, G. Planinšič, and E. Etkina, Am. J. Phys. 83, 366 (2015). 